\title{
Sero-Epidemiology of Marek's Disease Virus on Local and Exotic Chickens in Northwest Ethiopia
}

\author{
Mastewal Birhan ${ }^{1} *$ Nega Berhane ${ }^{1}$, Molalegne Bitew $^{2}$, Esayas Gelaye $^{3}$, Belayneh Getachew $^{3}$, Aragaw Zemene ${ }^{1}$, \\ Kassahun Birie ${ }^{4}$, Wudu Temesgen ${ }^{4}$ and Takele Abayneh ${ }^{3}$ \\ ${ }^{1}$ Institute of Biotechnology, University of Gondar, Ethiopia \\ ${ }^{2}$ Ethiopian Biotechnology Institute, Ethiopia \\ ${ }^{3}$ National Veterinary Institute, Ethiopia \\ ${ }^{4}$ College of Veterinary Medicine and Animal Sciences, University of Gondar, Ethiopia \\ *Corresponding author's Email: maste675@gmail.com; ORCID: 0000-0002-0984-5582
}

Received: 03 Jan. 2021

Accepted: 18 Feb. 2021

\begin{abstract}
Marek's disease (MD) is a lymphoproliferative and neuropathic disease of domestic fowl caused by alphaherpesviruses. The current cross-sectional study with a simple random sampling method was undertaken from January 2018 to May 2020. The current study aimed to estimate sero-epidemiology and assess potential risk factors, it is very important to determine MD sero-positivity. Moreover, to measure the association of host and environmental risk factors, the occurrences and spread of MD were identified in local and exotic chickens in Northwest Ethiopia. A total of 768 serum samples from 3 zones were collected and assayed for Marek's Disease Virus (MDV) antibodies using the indirect enzyme-linked immunosorbent assay test. A questionnaire survey was also conducted to gather information on the potential risk factors of MDV sero-positivity, as well as the status of occurrences and spread in the chicken flocks. In the present preliminary study, a high flock and chicken level of MDV was demonstrated, with an overall seroprevalence of $59.11 \%$. The mixed-effect logistic regression analysis of the host potential risk factors showed that the odds of seropositive for MD was significantly higher in local chickens (OR: 1.70, 95\% CI: 1.26-2.28) than exotic chickens, higher in chickens getting non-proper feed (OR: 0.26, 95\% CI: 0.13-0.54) than getting proper feed, higher in vaccinated chickens (OR: 1.04, 95\% CI: 0.76-1.43) than non-vaccinated chickens. Rearing chicken of different batches in one house was decreased the odds of occurrence of MD by 55\% (95\% CI: 0.38-0.80) than all-inall-out, higher in the well-ventilated type farms decreased the odds of occurrence of MD by $60 \%$ (95\% CI: 0.39-0.80) than in poor ones. Litter management when farmers used chickens as fertilizer has decreased the odds of occurrence of MD by 55\% (95\% CI: 0.01-0.47) and chickens were tossed into open sheds 40\% (95\% CI: 0.01-0.31), compared to buried chickens management. The study results indicated that the number of farms where farmers wearing no clothes and shoes (95\% CI: $0.10-0.58)$ were significantly decreased the occurrence of MD by $24 \%$ than those where farmers were equipped with clothes and shoes. The study area was highest in West Gojjam (OR: 0.40, 95\% CI: 0.27-0.58) and South Gondar (OR: 0.19, 95\% CI: 0.13-0.28) compared to North Gondar zone. In conclusion, the present study revealed a high flock and chicken seroprevalence level of MDV among chicken flocks in northwest Ethiopia, suggesting that environmental dust/dander and farm management systems might be a source of this disease for chicken infection. Besides, the observed association of MD, sero-positivity with environmental dust/dander, and farm management systems may suggest the economic importance of the disease for chicken production. Therefore, it warrants control attention to reduce its economic and disease spread burden in the study areas. Further works on the economic impacts, virus isolation, and molecular characterization of the disease are suggested.
\end{abstract}

Keywords: Chicken, Marek’s Disease, Northwest Ethiopia, Risk factors, Sero-epidemiology

\section{INTRODUCTION}

Marek's Disease Virus (MDV), recently classified as the Office International des Epizooties list B disease, and is a lymphoproliferative disease of chickens (Kamaldeep et al.,
2007; Couteaudier and Denesvre, 2014). Marek's Disease Virus is a highly cell-associated oncogenic $\alpha$-herpesvirus that causes immunosuppression (Puro et al., 2018), neurological disorders, chronic polyneuritis, lymphomas in 
visceral organs and other tissues, transient paralysis (Atkins et al., 2013; McPherson and Delany, 2016; Wang et al., 2018). The virus is transmitted to inexperienced chickens via the respiratory region (Witter and Burmester, 1967). Macrophages or dendritic cells subsequently transfer the virus to the major lymphoid organs (Woźniakowski and Samorek-Salamonowicz, 2014), where it infects B and T cells (Boodhoo et al., 2019). The route of infection is by inhalation of airborne cell-free virus particles within the contaminated dust and dander, and then shed from the infected host produced in terminally differentiated feather follicle epithelium, into a naive respiratory track (Boodhoo et al., 2016). The virus replicates within the feather follicle and spreads horizontally in poultry houses with dirt and dander (Davidson, 2019). It has a complex life with four main phases: an early cytolytic phase at 2-7 days post-infection (dpi) (Gurung et al., 2017), a latent section around 7-10 dpi, a late lysis section with the presence of tumors that are triggered between the 14 and $21 \mathrm{dpi}$, and a final proliferation section at $28 \mathrm{dpi}$. Throughout the primary lysis part, MDV preliminary uses B cells as targets for its replication before targeting activated CD4 $\mathrm{T}$ cells to adjust a persistent latent phase (Bai et al., 2019).

In infected chickens, unhealthful field strains of MDV will cause mortality of up to $100 \%$ in susceptible flocks; In infected chickens, unhealthful field strains of MDV will cause mortality of up to $100 \%$ in susceptible flocks; however, commercial losses due to MD are effectively controlled by the use of antigenically-related live attenuated vaccines (Cadmus et al., 2019; Neerukonda et al., 2019). In Ethiopia, the village system contributes to more than $90 \%$ of the national chicken meat and egg output (Ibrahim et al., 2019).

A number of challenges and obstacles warning the success and profitability of both backyard and semiintensive production have been identified, including infectious diseases, low effort of veterinary services, poor housing, poor biosecurity, predators, as well as the quality and cost of feed (Sambo et al., 2015). The economic encumbrance of MDV hail from both direct losses due to chicken mortality and morbidity (egg production loss) and indirect losses caused by the wide use of vaccines and control measures in the industry (Rozins et al., 2019). Furthermore, immunosuppression resulting in increased coexisting disease and decreases in weight gain are both important indirect effects associated with MDV infection (Atkins et al., 2013). The concentration of MDV in dust can vary by numerous orders of magnitude between farms and within the farms over time. The underlying cause of this variation is unknown (Kennedy et al., 2018). Periodic disease outbreaks always affect the chicken production system in Ethiopia in different ways by losing almost the entire flock in the village chicken. The other by the constant presence of infectious disease can lead not only to illness and death but also reduction of the product (Habte et al., 2017). The mortality rate due to natural MD challenge varied among four indigenous chickens in Ethiopia by ecotypes Fayoumi (94.8\%), Tepi (62.2\%), Horro (51.4\%), and Jarso (36.3\%) (Duguma et al., 2006), and the mortality rate was $46 \%$ (Lobago and Woldemeskel, 2004) in non-vaccinated poultry, and about $5 \%$ in MDV vaccinated chickens (Duguma et al., 2005). Nevertheless, estimates of overall mortality $(56.5 \%)$ and morbidity (58.1\%) were reported (Asfaw et al., 2021).

Amhara region also has the second $(10,368,274)$ reserves of poultry in Ethiopia (9,983,180 native breeds; 339,046 crossbreeds and 46,049 exotic breeds (Alemu et al., 2008). The majority (94-99\%) of the chicken population in Ethiopia was estimated as 49 million in 2011 (Sambo et al., 2015). More than 60\% of the Ethiopian families kept, managed, and controlled chickens as a source of income by selling them in cash (Dessie and Ogle, 2001). The reported mortality rate of Lohmann white breeds and Rhode Isle land Red were $29.34 \%$ and $16.18 \%$, respectively. The other mortality rate reported was also in exotic chickens in low altitude $(52.98 \%)$, (48.88\%), and mid-altitude (43.25\%) (Mazengia et al., 2012). In spite of their low productivity, and poultry health management, especially prevention, control of MDs was poor and particularly no seroprevalence study has been done in the northwest part of the country to address this issue. The findings of previous studies have shown that the seroprevalence of MDV antibodies in chickens ranges from $58 \%$ to $74.9 \%$. Within the country, the most important causes of MDV (feeding status, farm type, farm size, production type, rearing method, house sanitation, litter management, carcass management, and farm shoes and clothes within the flocks of chicken are not well documented, and also the association with the seroprevalence of MDV has not been well noted.

When the counts of chickens were high, the farmers did not benefit from the sector disease outbreak in Ethiopia (Yitbarek and Atalel, 2013). However, in the current study area, there was no clear evidence about MD challenges, epidemiological information, sero-prevalence, and status in Northwest Ethiopia.

In Ethiopia, greater efforts have been made to transform the production system into a more commercialized and intensive large-scale system but they 
have faced some challenges and serious problems that cause morbidities and mortalities in chickens, especially in the Northwest, Ethiopia. There was no enough data regarding the production constraints, opportunities, and MDV outbreak control for poultry production in the current study.

The current study was the first preliminary one in northwestern Ethiopia. Data on the seroprevalence of MDV in chickens would be caring for planning and implementing precautionary measures for economic impacts. Therefore, the objectives of the study were firstly to estimate the seroprevalence and the possible risk factors of MDV infection in local and exotic chickens in Northwest Ethiopia, and secondly to assess the relationship between sero-positivity of MDV through the environmental and management systems of farms for local and exotic chickens.

\section{MATERIAL AND METHODS}

Ethical approval

For the research team members to conduct the current study, after permitted ethical approval and statement given by the University of Gondar, Ethiopia. The current study was reviewed by the Institutional Ethical Review Board of the University of Gondar for its ethical soundness, and it is found to be ethically acceptable. Thus, the Research and Community Service Vice President Office has awarded on R. No. - O/V/PRCS/05/495/2018.

\section{Study areas}

Amhara Regional National State is located in the northwestern part of Ethiopia (Fentie et al., 2013). Study zones included North Gondar, West Gojjam, and South Gondar. According to Dachew and Bifftu (2014), North Gondar zone is located between geographically coordinates $12.3^{\circ}$ to $13.38^{\circ}$ north latitudes and $35.5^{\circ}$ to $38.3^{\circ}$ east longitudes. The altitude ranges from 550 meters below the sea level (masl) which is lowland (in western parts) and 4620 meters above the sea level (masl) which is highland (in the north part). The average annual rainfall varies from $880 \mathrm{~mm}$ to $1772 \mathrm{~mm}$, which is characterized by a monomodal type of distribution. The mean annual minimum and maximum temperatures are $10^{\circ} \mathrm{C}$ and $44.5^{\circ} \mathrm{C}$ in the highland and lowland, respectively. The indigenous chicken flock in the study zone was estimated at 3.75 million. Most of the poultry flocks were found in the highland and mid-highland areas of the region. This was due to the ecosystem and demography variations from low land. In this area, the local chickens were major poultry flocks in each household level as an income generation with a free-range production system (Fentie et al., 2013). According to Solomon et al. (2013), West Gojjam zone is situated at $11^{\circ} 09^{\prime} 60.00^{\prime \prime} \mathrm{N}$ latitude and $37^{\circ} 14^{\prime} 60.00^{\prime \prime} \mathrm{E}$ longitude with an altitude ranging from 1500 to $3420 \mathrm{~m}$ above the sea level. West Gojjam zone is one of the zones in Amhara Region where elevation varies from 1500 to 3500 m.a.s.l. Agriculture is the chief foundation to support the community (Motbaynor et al., 2020). South Gondar zone was encompassed in the study and is located in the Amhara Region, $660 \mathrm{~km}$ northeast of Addis Ababa, the Capital of Ethiopia. This Zone is wellknown with diverse topography ranging from flat and low grazing land to high cold mountains. The altitude is 1500 to 3,600 m.a.s.l. The average yearly rainfall varies from $700 \mathrm{~mm}$ to $1300 \mathrm{~mm}$ whereas the average daily temperature is $17^{\circ} \mathrm{C}$ in 2017 (Alelign et al., 2019).

\section{Study animals}

Seroprevalence investigation was conducted in a total of 768 chickens, where 384 local chickens and 384 exotic Sasso $\mathrm{T}$ lines (Ruby T) a dual-purpose chicken for meat and eggs, in a farm from Northwestern Ethiopia. Chickens were kept under intensive and extensive poultry farm management in the mixed production system of the area. Chickens, which two and above months of age were included in the sampling process. Farm rearing methods were all-in-all-out and different batches in one house.

\section{Study design and sample size}

A present cross-sectional study with a cluster random sampling was undertaken from January 2018 to May 2020. The sample size was calculated using a formula given by Greiner and Gardner (2000). Expected prevalence (Pexp) of $50 \%$, desired absolute precision (d), and a confidence level of $95 \%$ was determined by significance. Therefore, 384 Chickens were considered for sampling purposes. However, to account for the design effect associated with the clustering of study units within flocks and locations, the sample size was multiplied by two and the resulting in a total sample size of 768 Chickens.

\section{Blood sample collection and serum separation}

Whole blood samples (about 2-3 ml) were collected aseptically through wing vein puncture using $5 \mathrm{ml}$ plain vacationer tubes (Birhan et al., 2019). All necessary information related to each chicken included age, breed, sex, vaccine history, feeding status, farm type, farm size, production type, rearing method, house sanitation, litter management, house sanitation, ventilation type, zone, and 
farm shoes and cloth were properly labeled on the blood collection tubes and the data recording sheet. The blood samples were then allowed to clot in a slant position for a few minutes and centrifuged at $4000 \mathrm{rpm}$ for 5 minutes to separate the sera. Subsequently, sera were decanted into $1.5 \mathrm{ml}$ Eppendorf tubes and kept at $-20^{\circ} \mathrm{C}$ until the serological analysis for the presence of Marek's antibodies. In the attempts to screen and detect the MDV antibody at the National Veterinary Institute (NVI), all the materials were International Organization for Standardization. Regarding MD, the overall prevalence (Antibody prevalence) using indirect enzyme-linked immunosorbent assay was $59.11 \%$.

\section{Questionnaire survey}

A pretested semi-structured questionnaire survey was conducted during the blood sample collection by interviewing owners or attendants to assess the potential risk factors of MDV in chicken flocks. Farm supervisor veterinarians and farm owners were purposively selected. A total of 46 respondents were interviewed using semistructured questions for epidemiological data regarding total chickens, number of affected birds, number of birds reported dead due to MDV, age, breed, sex, vaccine history, feeding status and farm type, farm size, production type, rearing method, house sanitation, litter management, carcass management, and farm shoes and clothes as a source of the pathogen.

The hypothesized potential risk factors for MDV to assess included having information on the role of vaccine history, feeding status and farm type, farm size, rearing method, house sanitation, litter management, carcass management, and farm shoes and wearing as a source of a pathogen (yes/ no), flock size (50-200, 201-500 and $>501$ ), presence of a house as well for sick chickens in or around the farm (yes/no), presence of clothes and shoes for farm management (yes/no), chicken feed sources (properly feed and non-properly feed/millhouse grinder leftover), dead chickens' disposal method (buried, throw away in the field or use as fertilizer), and chicken feed contamination by dust/dander (yes/no). Moreover, the owners/attendants were interviewed about previous experiences of the occurrence of MDV transmissions at the flock/farm or individual chickens' level.

\section{Serological analysis}

Marek's disease virus Antibodies were assayed in the collected serum samples using the indirect ELISA kit test (Shenzhen Zhenrui Biotechnology Co., Ltd., China) following the previous reports (Zelnik et al., 2004) and manufacturer's recommendations. Indirect ELISA tests were detected using the naked eye and stereomicroscope. The presence of an indirect ELISA test was considered as positive at a titer of $>0.2$, and showed an antibody concentration equal to or greater than $100 \mathrm{ul}$. The flocks also were considered when at least one chicken was found positive. The laboratory procedures were performed at the NVI, Serology Laboratory.

\section{Data management and analysis}

The data generated was stored in the Microsoft Excel spreadsheet (2010), and analyzed using Stata software Version 16 for windows. The data were summarized using descriptive statistics. Seroprevalence of MDV infection was calculated by dividing the total number of seropositive chickens by the total number of examined poultry. Similarly, chicken flocks' seroprevalence was calculated as the total number of positive divided by the total number of the examined chicken flocks. Mixed effect logistic regression analysis was used to identify potential risk factors associated with MDV. First, invariable logistic regression analysis with the flock as a random effect was performed and potential risk factors (explanatory variables) with $\mathrm{p}$ values $\leq 0.25$ were screened for the multivariable mixed-effect logistic regression. Before running the multivariable mixed-effect logistic model, the explanatory variables were checked for multi-collinearity using the variance inflation factor (VIF) value of greater than 10 was considered the cut-off point for the collinearity diagnostics (Steinfeld et al., 2015). The associations were considered statistically significant when $\mathrm{P}<0.05$ at $95 \%$ confidence level. Odds ratios at a $95 \%$ confidence interval were used to express the strength of the risk of the diseases associated with the tested factors. Association of environmental risk factors (feeding status, farm type, farm size, rearing method, house sanitation, litter management, carcass management, and farm shoes and wearing as a source of a pathogen) with sero-positivity for MDV at flock level was analyzed similarly using mixed-effect logistic regression considering reproductive flosses as outcome variables and sero-positivity as the explanatory variable. The cutoff value of the receiver operating characteristic curve in the current study was $0.5 \%$ (Figure 1). This indicated that the expected probability from the model may have been a $50 \%$ probability of success.

The Area Under the Roc Curve (AUC) is an effective way to summarize the overall diagnostic test. It takes values from 0 (perfectly inaccurate test) to 1 (perfectly accurate test). The AUC can be computed using the general rules, 
in these rules the value of AUC (0.5) suggests no discrimination, 0.7-0.8 is considered acceptable, and 0.80.9 is considered excellent, and more than 0.9 is considered outstanding (Mandrekar, 2010). In dichotomous outcome (positive/negative test results) was used to plot sensitivity versus 1 -Specificity is called receiver operating characteristic (ROC) curve, and AUC, as an effective measure of the accuracy of meaningful interpretations (Hajian-Tilaki, 2013). The AUC was an effective way to summarize the overall diagnostic test. It takes values from 0 (perfectly inaccurate test) to 1(perfectly accurate test). Considering the obtained results of the current study, the AUC of the curve was 0.75. This suggested a $75 \%$ chance that the indirect ELISA test was correctly distinguished non-Marek's Disease from Marek's Disease chicken based on the standard of the optical density value with indirect ELISA reader. In this outcome, the result of sensitivity and specificity were $80.18 \%$ and $(54.46 \%)$, respectively, and also the correctly classified was $69.66 \%$. However, in this consequence of score value, the postulation was that indirect ELISA test was subjectively gives considered laboratory results of MD in chickens.

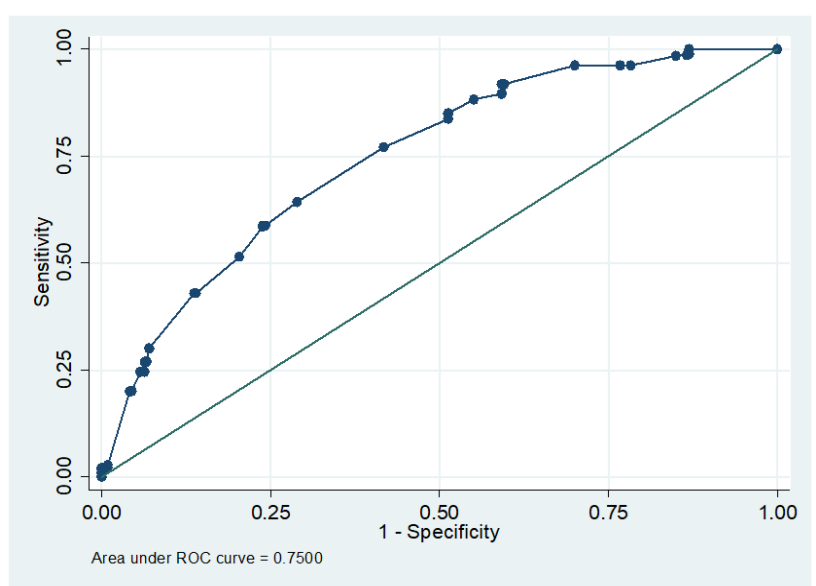

Figure 1. Receiver operator characteristic curve analysis and estimation of the study.

\section{RESULTS}

\section{Seroprevalence and host-related risk factor analysis}

A total of 768 serum samples were examined and 454 (59.11\%) were positive for MDV. As can be seen in Table
1 , the results of different age groups indicated a relatively higher prevalence of MDV in adult chickens $61.1 \%$ (0.610.57 ), compared to that of young age groups $52.7 \%$ ( 0.45 0.60). Similarly, a relatively higher prevalence of MDV was observed on the extensive farming system $(60.4 \%)$, as compared to that of the intensive $(55.6 \%)$ based on chicken farming systems. In the present study, different chicken farm sizes were examined, relatively a higher prevalence of MDV was observed in the medium farm's size $(66.2 \%)$, as compared to small (60.7\%) and large (25\%) farms size. Moreover, a relatively higher prevalence of the MDV was observed in the exotic breeds (67.7\%) than the local breeds (52.1\%). On the other hand, vaccinated chickens higher prevalence $(66.3 \%)$ than nonvaccinated ones $(53.7 \%)$.

The results presented in Table 1 indicated that there were statistically significant differences observed $(p<$ 0.05 ) among the prevalence of MDV, according to the age, breed, and vaccine history, feeding status, and rearing methods.

Questionnaire survey related to farm owners/attendants as risk factors for Marek's Disease Virus occurrences

A total of 46 chickens' farm owners/attendants participated in the questionnaire survey aimed at collecting data about potential risk factors for MDV. Out of 46 farm owners'/attendants' respondents, $69.57 \%$ did not know concerning the role of house litters and dust/dander as a pathogen source. All of them practiced an extensive management system. Among the respondents, $76.1 \%$ had no isolation house in their farms for diseased/sick chickens. The most frequently stated feeding status of chickens was properly fed $(83.6 \%)$ followed by nonproperly fed $(57.2 \%)$. Respondents also stated that litter management, including buried chickens, was $67 \%$ whereas chickens that accumulate near the farmhouse were $23.9 \%$ and the other that used chickens as fertilizer were $9.1 \%$. The respondents informed about rearing methods, different batches in one house were $71.74 \%$ and all-in-all-out methods were $28.3 \%$. The most accurate timetable for farm disinfections was $54.35 \%$, compared to the inaccurate timetable was $45.65 \%$. In the study areas, $10.87 \%$ of the farm owners/attendants dress in special clothes and shoes, but $89.13 \%$ were not used special clothes and shoes. 
Table 1. Invariable and multivariable mixed-effect logistic regression analysis of hosting potential risk factors for Marek's Disease Virus

\begin{tabular}{|c|c|c|c|c|c|c|c|c|}
\hline \multirow{2}{*}{ Variables } & \multirow{2}{*}{ Category } & \multirow{2}{*}{$\begin{array}{l}\text { Number of } \\
\text { examined }\end{array}$} & \multirow{2}{*}{$\begin{array}{l}\text { Number of } \\
\text { positive }\end{array}$} & \multirow{2}{*}{$\begin{array}{l}\text { Prevalence (\%) } \\
(95 \% \text { CI })\end{array}$} & \multicolumn{2}{|c|}{ Invariable } & \multicolumn{2}{|c|}{ Multivariable } \\
\hline & & & & & $\operatorname{COR}(95 \% \mathrm{CI})$ & p value & AOR $(95 \% \mathrm{CI})$ & p value \\
\hline \multirow{2}{*}{ Breed } & Exotic & 344 & 233 & $67.7(0.63-0.73)$ & 1.0 & & & \\
\hline & Local & 424 & 221 & $52.1(0.47-0.57)$ & $0.52(0.39-0.70)$ & $0.000 *$ & & \\
\hline \multirow{2}{*}{ Sex } & Male & 219 & 128 & $58.4(0.52-0.65)$ & 1.0 & & & \\
\hline & Female & 549 & 326 & $59.4(0.55-0.64)$ & $1.04(0.76-1.43)$ & 0.812 & & \\
\hline \multirow{2}{*}{ Farm Type } & Intensive & 198 & 110 & $55.6(0.49-0.63)$ & 1.0 & & & \\
\hline & Extensive & 570 & 344 & $60.4(0.56-0.64)$ & $1.22(0.87-1.86)$ & 0.237 & & \\
\hline \multirow{3}{*}{ Farm Size } & Small (50-200) & 567 & 344 & $60.7(0.57-0.65)$ & 1.0 & & & \\
\hline & Medium (201-500) & 145 & 96 & $66.2(0.58-0.74)$ & $1.27(0.87-1.86)$ & 0.221 & & \\
\hline & Large (>501) & 56 & 14 & $25(0.13-0.37)$ & $0.22(0.12-0.40)$ & $0.000 *$ & & \\
\hline \multirow{3}{*}{ Production Type } & Layer & 445 & 278 & $62.5(0.58-0.67)$ & 1.0 & & & \\
\hline & Broiler & 170 & 102 & $60(0.40-0.56)$ & $0.90(0.63-1.29)$ & 0.573 & & \\
\hline & Dual & 153 & 74 & $74(0.40-0.56)$ & $0.56(0.39-0.82)$ & 0.002 & & \\
\hline \multirow{2}{*}{ Age } & Young & 184 & 97 & $52.7(0.45-0.60)$ & 1.0 & & & \\
\hline & Adult & 584 & 357 & $61.1(0.61-0.57)$ & $1.41(1.01-1.97)$ & 0.043 & $0.41(0.20-0.87)$ & 0.020 \\
\hline \multirow{2}{*}{ Vaccination history } & Vaccinated & 436 & 234 & $53.7(40.49-0.58)$ & 1.0 & & & \\
\hline & Non-Vaccinated & 332 & 220 & $66.3(0.61-0.71)$ & $1.70(1.26-2.28)$ & $0.000 *$ & $2.15(1.54-2.99)$ & $0.000 *$ \\
\hline \multirow{2}{*}{ Feeding Status } & Properly Feed & 55 & 46 & $83.6(0.74-0.94)$ & 1.0 & & & \\
\hline & Non-Properly Feed & 713 & 408 & $57.2(0.54-0.61)$ & $0.26(0.13-0.54)$ & $0.000 *$ & & \\
\hline \multirow[b]{2}{*}{ Rearing Method } & All-in-All-out & 157 & 110 & $70.1(0.63-0.77)$ & 1.0 & & & \\
\hline & $\begin{array}{l}\text { Different Batches in One } \\
\text { House }\end{array}$ & 611 & 344 & $56.3(0.52-0.60)$ & $0.55(0.38-0.80)$ & 0.002 & & \\
\hline
\end{tabular}

COR: Crude odds ratio, AOR: Adjusted odds ratio, CI: Confidence Interval, $\mathrm{p}$ values $\leq 0.05$ was statistically significant, $\mathrm{p}$ values $=0.00^{*}$ were strongly significant. 
Table 2. Invariable and multivariable mixed-effect logistic regression analysis of environmental risk factors for Marek's Disease Virus

\begin{tabular}{|c|c|c|c|c|c|c|c|c|}
\hline \multirow{2}{*}{ Variables } & \multirow{2}{*}{ Category } & \multirow{2}{*}{$\begin{array}{l}\text { Number of } \\
\text { examined }\end{array}$} & \multirow{2}{*}{$\begin{array}{l}\text { Number of } \\
\text { positive }\end{array}$} & \multirow{2}{*}{$\begin{array}{l}\text { Prevalence (\%) } \\
\quad(95 \% \text { CI })\end{array}$} & \multicolumn{2}{|c|}{ Invariable } & \multicolumn{2}{|c|}{ Multivariable } \\
\hline & & & & & COR $(95 \% \mathrm{CI})$ & p value & $\operatorname{AOR}(95 \% \mathrm{CI})$ & p value \\
\hline \multirow{2}{*}{ Ventilation Type } & Good & 609 & 378 & $48(0.40-0.56)$ & 1.0 & & & \\
\hline & Poor & 159 & 76 & $62.1(0.58-0.66)$ & $0.56(0.39-0.80)$ & 0.001 & & \\
\hline \multirow{2}{*}{ House Sanitation } & Good & 448 & 252 & $47.8(0.40-0.56)$ & 1.0 & & & \\
\hline & Poor & 320 & 202 & $56.3(0.52-0.61)$ & $1.33(0.99-1.79)$ & 0.056 & $0.17(0.07-0.33)$ & $0.000 *$ \\
\hline \multirow{3}{*}{ Litter Management } & Buried & 25 & 24 & $63.1(0.58-0.68)$ & 1.0 & & & \\
\hline & Use as fertilizer & 570 & 344 & $96(0.88-1.04)$ & $0.06(0.01-0.47)$ & 0.007 & & \\
\hline & Accumulate near space & 173 & 86 & $60.4(0.56-0.64)$ & $0.04(0.01-0.31)$ & 0.002 & & \\
\hline \multirow{3}{*}{ Zone } & North Gondar & 256 & 200 & $78.1(0.73-0.83)$ & 1.0 & & & \\
\hline & South Gondar & 256 & 104 & $40.6(0.35-0.47)$ & $0.19(0.13-0.28)$ & $0.000 *$ & $0.05(0.03-0.10)$ & $0.000 *$ \\
\hline & West Gojjam & 256 & 150 & $58.6(0.53-0.65)$ & $0.40(0.27-0.58)$ & $0.000 *$ & $0.07(0.03-0.15)$ & $0.000^{*}$ \\
\hline \multirow{2}{*}{ Farm Shoes and clothes } & Have & 40 & 34 & $60.4(0.57-0.65)$ & 1.0 & & & \\
\hline & Have-No & 728 & 420 & $85(0.73-0.97)$ & $0.24(0.10-0.58)$ & 0.002 & $0.10(0.034-0.27)$ & $0.000 *$ \\
\hline
\end{tabular}

COR: Crude odds ratio, AOR: Adjusted odds ratio, CI: Confidence Interval, $\mathrm{p}$ values $\leq 0.05$ was statistically significant, $\mathrm{p}$ values $=0.00 *$ were strongly significant. 


\section{DISCUSSION}

Chicken production is the distinctive local economic development of urban centers through the development of related micro-enterprises wholly or partly responsible for the provision of inputs and processing, packaging, and marketing of outputs as well as the delivery of services to the sector (Ebsa et al., 2019). The current study has indicated the widespread occurrence of MDV infection in the chicken flock in northwest Ethiopia with a high seroprevalence of $59.11 \%$. This coincides with the previous studies in Ethiopia, which similarly reported high seroprevalence of MDV in chickens (Duguma et al., 2005). Similarly, the present findings are compatible with the reports of Oni and Owoade (2009) and Wajid et al. (2013) from Nigeria, and Wajid et al. (2013) from Southern Iraq. However, the current result was higher than other previous reports from the Central African Republic (Snoeck et al., 2012), and lower than reports from Tanzania (Sailen et al., 2017).

In fact, many factors attributed to why the results of the current study differ from other findings. Considering the investigated factors, different diagnostic test kits, the diverse geographical location and climate changes of the study, and the distinctive farm management system can be listed. The variation observed among the different studies in the prevalence of MDV might be due to the difference in the breed, management system, and the epidemiological status of the animals among the different study areas.

Among the risk factors considered in the current study, age, breed, vaccination history, feeding status, rearing method, litter management, ventilation type, zone, and farm shoes and wearing were found to be statistically significant $(\mathrm{P}<0.05)$. There was a significant difference in the prevalence among chickens of different ages $(\mathrm{P}<$ $0.05)$. The highest prevalence $(61.1 \%)$ was found in adult chickens, followed by the lowest prevalence $(52.7 \%)$ in young chickens. The high prevalence of the MDV revealed in adult chickens might be due to the physiology of the exhausted canal which is more dilated, and remains partially open because there have been years of repeated exposure, and it is a chronic disease. Susceptibility to MDV was considered to be much higher in older chickens than in younger ones. Although the age-resistance remained unclear, the immune system maturation likely participated in this event. Marek's disease virus can occur at any time, beginning at 3-4 weeks of age (Ikezawa et al., 2010).

However, there were significant differences in the occurrence of MD between exotic and local breed outcomes (Table 1). A higher prevalence $(67.7 \%)$ was recorded in the exotic breed, and a lower prevalence $(52.1 \%)$ was verified in chickens with the local breed. Due to low genetic-diseases-resistant and other environmental stress, exotic breeds were high exposed than local breeds (Duguma et al., 2005).

Furthermore, non-vaccinated chickens $(66.3 \%)$ were more susceptible and had the chance of acquiring the MD, whereas the vaccinated chickens $(53.7 \%)$ less susceptible. However, vaccines are commonly used in the commercial poultry industry because small numbers of doses cannot be purchased for use. The best protection mechanism for the backyard chicken's management systems is to disinfect the area. Predominantly the commercial flocks, it is important to have proper biosecurity to ensure that vaccinated chickens will develop immunity before they are exposed to a severe challenge of MDV (Mazengia, 2012).

Among the environmental risk factors, feeding status, rearing method, ventilation type, litter man management system, and farm shoes and wearing were statistically significant $(P<0.05$, Table 2$)$. Since chickens are required to be reared separately, they are free from the infected fluff and dust of older birds. Standard hygiene measures are also important, including a thorough clean-out and disinfection of the sheds and equipment among batches of chickens with a disinfectant effective against viruses. Decent nutrition and maintenance of freedom from other diseases and parasites are also vital. These practices will help to maintain the flock's health, and ensure that the birds have optimum resistance against MD infection (Rwuaan et al., 2012). The virus matures into a fully infective, enveloped form in the epithelium of the feather follicle, from which it is released into the environment (Morrow and Fehler, 2004).

The current study showed significant results among various zones $(\mathrm{P}<0.05)$. A higher prevalence was recorded in the north Gondar zone (78.1\%) followed by the West Gojjam zone (58.6\%) and South Gondar zone $(40.6 \%)$, respectively. According to these studies, this might be associated with the herding practices of chickens. The absence of research-based investigation approaches resulted in a lack of knowledge of the prevalent strain of viruses and information on the overall epidemiological patterns of the MDV (Witter et al., 1970).

\section{CONCLUSION}

In conclusion, the current preliminary study revealed a high seroprevalence of Marek's disease (MD) in the chicken flocks in northwest Ethiopia, suggesting that by 
applying proper farm management systems with biosecurity, such as Good rearing method, litter management, and follow up seasonal vaccines, the disease can be prevented and controlled. The study also demonstrated that sero-positivity for MDV was associated with age, breed, and vaccine history, feeding status, rearing method, litter management, ventilation type, zone, and farm shoes and wearing with an important economic significance for poultry farm owners. Therefore, it warrants control to reduce its economic and disease burden. Further works on the virus isolation and economic impacts are needed in the study area and it is also given attention to further investigation on the effectiveness of vaccines and their delivery system. In order to know the circulation virus and strain type, the molecular study of the diseases is suggested.

\section{DECLARATIONS}

\section{Acknowledgments}

This Ph.D. work was supported by the University of Gondar (Institute of Biotechnology), research and community service vice president office, Ethiopian. Moreover, material and financial provisions were sponsored by National Veterinary Institute and Ethiopian Biotechnology Institute together.

\section{Authors' contributions}

Mastewal Birhan, Nega Berhane, Molalegne Bitew, Esayas Gelaye, and Takele Abayneh are substantial contributors to the conception and design, acquisition of data, or analysis and interpretation of data, drafting the article or revising it critically for important intellectual content. Belayneh Getachew, Aragaw Zemene, Kassahun Birie, and Wudu Temesgen are given some technical comments. Mastewal Birhan, Nega Berhane, Molalegne Bitew, Esayas Gelaye, and Takele Abayneh approved the final draft of the manuscript to be published and agreed to be accountable for all aspects of the work in ensuring that questions related to the accuracy or integrity of any part of the work are appropriately investigated and resolved.

\section{Competing interests}

All authors declare that they have no competing interests.

\section{REFERENCES}

Alelign A, Zewude A, Petros B, and Ameni G (2019). Tuberculosis at farmer-cattle interface in the rural villages of South Gondar zone of
Northwest Ethiopia. Tuberculosis Research and Treatment, Article ID 2106981. DOI: https://www.doi.org/10.1155/2019/2106981

Alemu D, Degefe T, Ferede S, Nzietchueng S, and Roy D (2008). Overview and background paper on Ethiopia's poultry sector: Relevance for Hpai Research in Ethiopia, pp. 52-60. Available at: https://cgspace.cgiar.org/handle/10568/488

Asfaw YT, Ameni G, Medhin G, Gumi B, Hagos Y, and Wieland B (2021). Poultry disease occurrences and their impacts in Ethiopia. Tropical Animal Health and Production, 53(1): Article number 54. DOI: https://www.doi.org/10.1007/s11250-020-02465-6

Atkins KE, Read AF, Walkden-Brown SW, Savill NJ, and Woolhouse ME (2013). The effectiveness of mass vaccination on Marek's dsease virus (Mdv) outbreaks and detection within a broiler barn: A modeling study. Epidemics, 5(4): 208-217. DOI: https://www.doi.org/10.1016/j.epidem.2013.10.001

Bai H, He Y, Ding Y, Carrillo JA, Selvaraj RK, Zhang H, Chen J, and Song J (2019). Allele-specific expression of $\mathrm{Cd} 4+\mathrm{T}$ cells in response to Marek's disease virus infection. Genes, 10(9): 718. DOI: https://www.doi.org/10.3390/genes10090718

Birhan M, Birhan M, Tesfaye S, and Tariku A (2019). Detection of antibodies against newcastle and infectious bursal disease on chicken in North Gondar Zone, Ethiopia. Online Journal of Animal and Feed Research, 9(2): 51-58. PII: S222877011900008-9

Boodhoo N, Gurung A, Sharif S, and Behboudi S (2016). Marek's disease in chickens: a review with focus on immunology. Veterinary Research, 47: Article number 119. DOI: https://www.doi.org/10.1186/s13567-016-0404-3

Boodhoo N, Kamble N, Kaufer BB, and Behboudi S (2019). Replication of Marek's disease virus is dependent on synthesis of de novo fatty acid and prostaglandin E2. Journal of Virology, 93(13): e00352-19. DOI: https://www.doi.org/10.1128/JVI.00352-19

Cadmus KJ, Mete A, Harris M, Anderson D, Davison S, Sato Y, Helm J, Boger L, Odani J, and Ficken MD (2019). Causes of mortality in backyard poultry in eight states in the United States. Journal of Veterinary Diagnostic Investigation, 31(3): 318-326. DOI: https://www.doi.org/10.1177/1040638719848718

Couteaudier M, and Denesvre C (2014). Marek's disease virus and skin interactions. Veterinary Research, 45: Article number 36. DOI: Ihttps://www.doi.org/10.1186/1297-9716-45-36

Dachew BA, and Bifftu BB (2014). Breastfeeding practice and associated factors among female nurses and midwives at North Gondar Zone, Northwest Ethiopia: a cross-sectional institution based study. International Breastfeeding Journal, 9(11): 1-7. DOI: https://doi.org/10.1186/1746-4358-9-11.

Davidson I (2019). Biotic concerns in generating molecular diagnosis matrixes for 4 avian viruses with emphasis on Marek's disease virus. Journal of Virological Methods, 274: 113708. DOI: https://www.doi.org/10.1016/j.jviromet.2019.113708

Dessie T, and Ogle B (2001). Village poultry production systems in the central highlands of Ethiopia. Tropical Animal Health and Production, 33: 521-537. DOI: https://www.doi.org/10.1023/A:1012740832558

Duguma R, Dana N, and Yami A (2006). Marek's disease vaccination opened the door to rear indigenous chickens of Ethiopia under confined management. International Journal of Applied Research in Veterinary Medicine, 4(2): 121-127. Available at: http://www.jarvm.com/articles/Vol4Iss2/Duguma.pdf

Duguma R, Yami A, Dana N, Hassen F, and Esatu W (2005). Marek's disease in local chicken strains of Ethiopia reared under confined management regime in central Ethiopia. Revue De Medicine Veterinary, 156(11) 541-546. Available at: https://research.wur.nl/en/publications/mareks-disease-in-localchicken-strains-of-ethiopia-reared-under-

Ebsa YA, Harpal S, and Negia GG (2019). Challenges and chicken production status of poultry producers in Bishoftu, Ethiopia. 
Poultry Science, 98(11): 5452-5455. DOI: https://www.doi.org/10.3382/ps/pez343

Fentie T, Abebe B, and Kassa T (2013). Small-scale family poultry production in North Gondar: characteristics, productivity and constraints. Livestock Research for Rural Development, 25(9): Article \#161. Available at: http://lrrd.cipav.org.co/lrrd25/9/fent25161.htm

Greiner M, and Gardner IA (2000). Application of diagnostic tests in veterinary epidemiologic studies. Preventive veterinary medicine, 45(1-2), pp.43-59. DOI: https://www.doi.org/10.1016/S0167$\underline{5877(00) 00116-1 .}$.

Gurung A, Kamble N, Kaufer BB, Pathan A, and Behboudi S (2017). Association of Marek's disease induced immunosuppression with activation of a novel regulatory T cells in chickens. Plos Pathogens, 13: e1006745. DOI: https://www.doi.org/10.1371/journal.ppat.1006745

Habte T, Amare A, Bettridge J, Collins M, Christley R, and Wigley P (2017). Guide to chicken health and management in Ethiopia. Ilri Manual, 25: 1-25. Available at: https://cgspace.cgiar.org/rest/rest/bitstreams/145486/retrieve

Hajian-Tilaki K (2013). Receiver operating characteristic (ROC) curve analysis for medical diagnostic test evaluation. Caspian journal of internal medicine, 4(2): 627. Available at: https://www.ncbi.nlm.nih.gov/pmc/articles/PMC3755824/

Ibrahim D, Goshu G, Esatu W, and Cahaner A (2019). Dual-purpose production of genetically different chicken crossbreeds in Ethiopia. 1. Parent stocks' feed intake, body weight, and reproductive performance. Poultry Science, 98(8): 3119-3129. DOI: https://www.doi.org/10.3382/ps/pez136

Ikezawa M, Goryo M, Sasaki J, Haridy M, and Okada K (2010). Late Marek's Disease in adult chickens inoculated with virulent Marek's disease virus. Journal of Veterinary Medical Science, 72(12):15391545. DOI: https://www.doi.org/10.1292/jvms.10-0203

Kamaldeep P, Sharma C, and Narang G (2007). Occurrence of Marek's disease in vaccinated poultry flocks of Haryana (India). International Journal of Poultry Science, 6(5): 372-377. DOI: https://www.doi.org/10.3923/ijps.2007.372.377

Kennedy DA, Dunn PA, and Read AF (2018). Modeling Marek's disease virus transmission: A framework for evaluating the impact of farming practices and evolution. Epidemics, 23: 85-95. DOI: https://www.doi.org/10.1016/j.epidem.2018.01.001

Lobago F, and Woldemeskel M (2004). An outbreak of Marek's disease in chickens in central Ethiopia. Tropical Animal Health and Production, 36(4): 397-406. DOI: https://www.doi.org/10.1023/B:TROP.0000026665.78878.f4

Mandrekar JN (2010). Receiver operating characteristic curve in diagnostic test assessment. Journal of Thoracic Oncology, 5(9): 1315-1316. https://www.doi.org/10.1097/JTO.0b013e3181ec173d

Mazengia H (2012). Review on major viral diseases of chickens reported in Ethiopia. Journal of Infectious Diseases and Immunity, 4(1): 1-9. DOI: https://www.doi.org/10.5897/JIDIx11.001

Mazengia H, Siraw G, and Nega M (2012). Challenges and prospects of village-based exotic chicken development strategy in Amhara regional state, Northwest Ethiopia. Global Journal of Science Frontier Research Agriculture and Veterinary Sciences, 12(10): 41$49 . \quad$ Available https://journalofscience.org/index.php/GJSFR/article/view/547

Mcpherson M, and Delany M (2016). Virus and host genomic, molecular, and cellular interactions during Marek's disease pathogenesis and oncogenesis. Poultry Science, 95: 412-429. DOI: https://www.doi.org/10.3382/ps/pev369

Morrow C, and Fehler F (2004). Marek's Disease: A Worldwide Problem. Marek's Disease. Elsevier. Biology of Animal Infections, pp. 49-61. DOI: https://www.doi.org/10.1016/B978-012088379$\underline{0 / 50009-8}$

Motbaynor MM, Tadesse NS, Gashaw AM, and Hailu AA (2020). Documentation of traditional knowledge associated with medicinal animals in West Gojjam Zone of Amhara Region, Ethiopia, pp. 28. DOI: https://doi.org/10.21203/rs.3.rs-31098/v1

Neerukonda SN, Tavlarides-Hontz P, Mccarthy F, Pendarvis K, and Parcells MS (2019). Comparison of the transcriptomes and proteomes of serum exosomes from Marek's disease virusvaccinated and protected and lymphoma-bearing chickens. Genes, 10(2): 116. DOI: https://www.doi.org/10.3390/genes10020116

Oni O, and Owoade A (2009). Seroprevalence of Marek's Disease Virus Antibody in Some Poultry Flocks in Southwestern Nigeria. Animal Production Research Advances, 5(1): 41-49. DOI: https:// www.doi.org/10.4314/apra.v5i1.49816

Puro KU, Bhattacharjee U, Baruah S, Sen A, Das S, Ghatak S, Doley S, Sanjukta R, and Shakuntala I (2018). Characterization of Marek's disease virus and phylogenetic analyses of meq gene from an outbreak in poultry in Meghalaya of Northeast India. Virus Disease, 29: 167-172. DOI: https://www.doi.org/10.1007/s13337-018-0448$\underline{2}$

Rozins C, Day T, and Greenhalgh S (2019). Managing Marek's Disease in the Egg Industry. Epidemics, 27: 52-58. DOI: https://www.doi.org/10.1016/j.epidem.2019.01.004

Rwuaan J, Rekwot P, and Omontese B (2012). Effect of a velogenic newcastle disease virus on body and organ weights of vaccinated Shika brown cocks. Sokoto Journal of Veterinary Sciences, 10(2): 7-12. DOI: https://www.doi.org/10.4314/sokjvs.v10i2.2

Sailen A, Marisa J, Masanja P, Mchonde S, and Anderson M (2017). Trends in diagnosis of Marek's disease (Md) in poultry at Central Veterinary Laboratory in Dar Es Salaam, Tanzania. Tanzania Veterinary Journal, 35: 54-57. Available at: https://www.ajol.info/index.php/tvj/article/view/179108

Sambo E, Bettridge J, Dessie T, Amare A, Habte T, Wigley P, and Christley RM (2015). Participatory evaluation of chicken health and production constraints in Ethiopia. Preventive Veterinary Medicine, 118(1): 117-127. DOI: https://www.doi.org/10.1016/j.prevetmed.2014.10.014

Snoeck CJ, Komoyo GF, Mbee BP, Nakouné E, Le Faou A, Okwen MP, and Muller CP (2012). Epidemiology of chicken anemia virus in Central African Republic and Cameroon. Virology Journal, 9: Article number 189. DOI: https://www.doi.org/10.1186/1743422X-9-189

Solomon A, Workalemahu A, Jabbar MM, Ahmed MA, and Hurissa B (2003). Livestock marketing in Ethiopia: A review of structure, performance, and development initiatives, Socio-economics and policy research working paper 52. ILRI (International Livestock Research Institute), Nairobi, Kenya, pp. 1-35. Available at: http://www.fao.org/fileadmin/templates/agphome/images/iclsd/doc uments/wk2_c5_gerard.pdf

Steinfeld B, Scott J, Vilander G, Marx L, Quirk M, Lindberg J, and Koerner K (2015). The role of lean process improvement in implementation of evidence-based practices in behavioral health care. The Journal of Behavioral Health Services and Research, 42: 504-518. DOI: https://www.doi.org/10.1007/s11414-013-9386-3

Wajid SJ, Katz ME, Renz KG, and Walkden-Brown SW (2013). Prevalence of Marek's Disease Virus in Different Chicken Populations in Iraq and Indicative Virulence Based on Sequence Variation in the Ecori-Q (Meq) Gene. Avian Diseases, 57(2): 562568. DOI: https://www.doi.org/10.1637/10342-083112-Reg.1

Wang D, Sun S, and Heidari M (2018). Marek's disease vaccine activates chicken macrophages. Journal of Veterinary Science, 19(3): 375383. DOI: https://www.doi.org/10.4142/jvs.2018.19.3.375

Witter R, and Burmester B (1967). Transmission of Marek's disease with oral washings and feces from infected chickens. Proceedings of the 
Society for Experimental Biology and Medicine, 124: 59-62. DOI: https://www.doi.org/10.3181/00379727-124-31666

Witter R, Moulthrop Jr J, Burgoyne G, and Connell H (1970). Studies on the epidemiology of Marek's disease herpesvirus in broiler flocks. Avian Diseases, 14(2): 255-267. DOI: https://www.doi.org/10.2307/1588470

Woźniakowski G, and Samorek-Salamonowicz E (2014). Direct Detection of Marek's disease virus in poultry dust by loop-mediated isothermal amplification. archives of Virology, 159: 3083-3087. DOI: https://www.doi.org/10.1007/s00705-014-2157-5
Yitbarek MB, and Atalel W (2013). Constraints and opportunities of village chicken production in debsan tikara keble at Gonder Zuria Woreda, North Gonder, Ethiopia. Scientific Journal of Veterinary Advances, 2(8): $118-124$.

DOI: https://www.doi.org/10.14196/sjvs.v2i8.965

Zelnik V, Harlin O, Fehler F, Kaspers B, Göbel T, Nair V, and Osterrieder N (2004). An enzyme-linked immunosorbent assay (ELISA) for detection of Marek's disease virus-specific antibodies and its application in an experimental vaccine trial. Journal of Veterinary Medicine, Series B, 51(2): 61-67. DOI: https://www.doi.org/10.1111/j.1439-0450.2004.00728 